\title{
ESTADO E CULTURA: MANIFESTAÇÕES CULTURAIS TRADICIONAIS E AS POLÍTICAS PÚBLICAS DE CULTURA
}

\author{
Dedival Brandão da SILVA ${ }^{1}$ \\ Universidade Federal do Pará/UFPA \\ dedivalbs@ufpa.br
}

Resumo: Este artigo tem por objeto de estudo a situação crítica existente entre poder público e as culturas populares no que diz respeito à (in)existência de políticas públicas na área de manifestações tradicionais como o carnaval, em Abaetetuba. Apresenta como proposta de análise do problema examinar a noção de cultura popular enquanto produto e enquanto processo, apontando a necessidade de reconhecer sua dimensão social; em seguida, descreve aspectos do carnaval da cidade marcando qual tem sido o olhar do poder público em relação a essa prática social. Finalmente, aponta a inexistência de políticas públicas orgânicas no Município para tratar dos fatos da cultura tradicional do carnaval, indicando ser este o fator de desmobilização dos movimentos populares em detrimento dos movimentos da indústria cultural das micaretas. No plano metodológico, a concepção teórica da abordagem recaiu na perspectiva da teoria antropológica da cultura, com base em dados etnográficos. Tal procedimento permitiu concluir que existe uma compreensão reificada da cultura pelo poder público, que em vez de tratá-la enquanto sistema de representação a considera apenas no nível do senso comum, em cuja perspectiva ela corresponderia apenas a expressões culturais como produto a ser exibido, gerando a desimportância dessas práticas.

Palavras-Chave: Culturas populares. Escolas de samba. Políticas públicas. Indústria cultural.

Abstract: This article aims to study the existing critical situation between government and popular cultures with regard to the (in) existence of public policies in the area of traditional events like Carnival in Abaetetuba. Presents as proposed problem analysis to examine the notion of popular culture as a product and as a process, highlighting the need to recognize the social dimension; then describes aspects Town Carnival checking what has been the eye of the government in relation to this social practice. Finally, it addresses the lack of

\footnotetext{
1 Professor da Faculdade de Educação e Ciências Sociais - FAECS/Campus Universitário de Abaetetuba/UFPA, Área de Antropologia e Educação.
} 


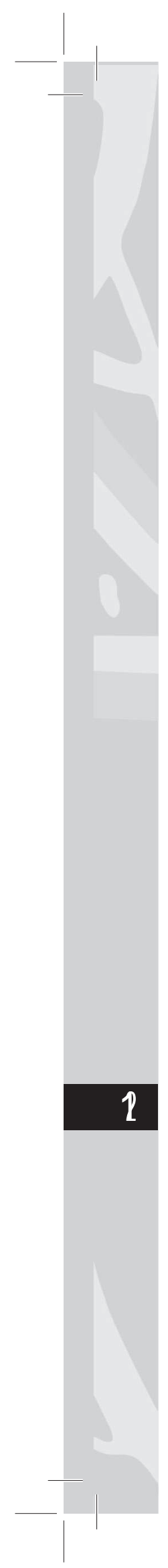

organic public policy in the City to address the facts of the traditional culture of the carnival, indicating that this factor demobilizing popular movements rather than the movements of the cultural industry of micaretas. At the methodological level, the theoretical conception of the approach fell from the perspective of anthropological theory of culture, based on ethnographic data. This procedure allowed us to conclude that there is a reified understanding of culture by the government, rather than treat it as a representation of the system only considers the level of common sense, on whose perspective it would only match the cultural expressions as a product to be displayed, generating the unimportance of these practices.

Keywords: Popular culture. Samba schools. Public policy. Cultural industry.

\section{Introdução}

Segundo observei em outro estudo ${ }^{2}$, as relações existentes entre as culturas populares e o poder público sempre foram críticas. Tais dificuldades podem assumir duas dimensões: ora o Estado não participa de suas dimensões políticas ao lidar com elas e quando as trata o faz procurando sempre negar a dimensão social da própria cultura, passando esta a ser compreendida tão-somente enquanto produto. Ou seja, um trabalho morto produzido e deixado pelo homem em vez de tratá-las sob o ponto de vista de sua processualidade histórica. ${ }^{3}$

Este fato tem trazido como resultado o desencadeamento de um processo caracterizado pelo esvaziamento de algumas manifestações culturais tradicionais como é o caso do quadro que o carnaval assumiu na cidade de Abaetetuba no último decênio (20042014).

A proposta deste artigo é tomar por baliza a situação crítica apontada e destacar alguns pontos que possam esclarecer aquelas duas situações, bem como avaliar de que maneira elas podem ser

\footnotetext{
${ }^{2}$ Cf. Migalhas do carnaval. Escolas de samba, educação e patrimônio etnográfico em Abaetetuba. 2014, cap. 2.

${ }^{3}$ Cf. Brandão, C. Rodrigues. Cultura, estado e sociedade. In: O Ardil da Ordem. Campinas, São Paulo: Papirus, 1983. p. 52-53.
} 
tradutoras ou não do modus operandi de políticas públicas voltadas às culturas populares na cidade. Parte-se, inicialmente, de uma concepção de cultura popular e, em seguida, ao retratar a experiência do carnaval de Abaetetuba em um período de dez anos, avalia o olhar do poder público sobre ela; finalmente, busca-se apontar algumas implicações que a ausência de políticas públicas de cultura trazem à cidade assim como ao carnaval tradicional avaliando suas implicações político-ideológicas.

\section{Culturas populares: do produto ao processo}

Num importante estudo, o antropólogo Antônio Augusto Arantes (1995), observa de que forma a cultura popular assume visões valorativas contribuindo à reificação do processo cultural. Para o autor, esta seria apresentada como suporte de um não saber, como algo desprovido de significado, dando margem a especulação que "o povo não tem cultura"; ora ela apresentar-se-ia como suporte de tradição, porém, está sendo considerada como algo imutável no tempo.

Nesse quadro, as culturas populares equivaleriam ao folclore, porém, este identificado objetos, práticas, concepções religiosas, estáticas e tradicionais. Enfim, a cultura popular enquanto tradição equivaleria a uma outra cultura. A ideia de tradição traria em seu bojo o significado segundo o qual sua idade de ouro segundo afirma aquele autor, ocorrera no passado, as mudanças seriam deturpadoras e empobrecedoras, assim como a pesquisa equivaleria a simples listagem e classificação de objetos, textos e danças populares, cujo processo final é a reprodução do produto. Em ambos os casos, fica revelado seu caráter cristalizado e imutável face às transformações sociais.

Dessa forma, o autor propõe como alternativa um projeto de cultura segundo o qual o foco de atenção deveria ser sobre "o que as culturas efetivamente são, ou melhor, sobre como elas são produzidas, sobre os processos através dos quais elas se constituem e o que elas 


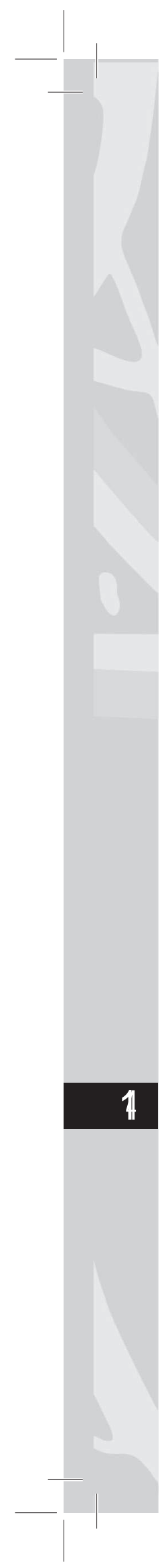

expressam, e não sobre o que elas foram, seriam ou deverão ser" (ARANTES, op. cit. p. 57. Grifo no original).

Compartilhando dessa perspectiva no sentido de propor uma desnaturalização para a cultura, Alfredo Bosi em "Cultura como tradição" (1987), chama a atenção para a importância da concepção ergótica do processo cultural. Ou seja, a noção de cultura enquanto resultado de uma conquista, como ação e trabalho, imprimindo às práticas sociais uma dimensão mais humanista e democrática. Esta perspectiva desloca a ideia de mercadoria a ser exibida (típica da visão reificada de cultura), equivalente a um conjunto de coisas desfrutáveis, uma soma de objetos, para a ideia de trabalho a ser empreendido. Assim sendo, o que interessa na cultura seria o fazer em vez da aquisição de objetos. Ela não deve ser fetichista, dado que opera com significados. Tais noções vêm ao encontro de uma outra concepção antropológica de cultura segundo a qual a vida social é ordenada por meio de símbolos, organizada em sistemas. Ou, ainda, que a cultura não está em um nível próprio da vida social, e sim em todas as esferas do social; é o elo de significação que permite entender o que acontece ao redor dos indivíduos, como bem observou alhures o antropólogo americano Clifford Geertz, em seu clássico estudo "As interpretações da cultura" (1978).

Enquanto lugar de produção cultural, o "popular" e suas práticas ao ocorrerem na esfera do cotidiano, este assume uma dimensão política dado que é na dimensão cotidiana da vida social que indivíduos e grupos reordenam suas vidas, recriam suas possibilidades de existência e investem naquilo que acreditam dando assim sentido às suas práticas.

É possível inferir que a dimensão social da cultura não raro negada pelo Estado (restrição às formas de produção, limitação ao incentivo a projetos culturais, inexistência de planos municipais de cultura e de políticas públicas na área) ganha ali sua significância, porquanto detentora de um saber e, ao colocar em prática esses saberes, 
exerce sua função social de humanização dos sujeitos, marcando o posicionamento de indivíduos e grupos na cena urbana. Assim, os valores e as significâncias das práticas construídas na teia das relações sociais e que estão presentes na dimensão social da cultura residem no fato que a mesma em sua dinâmica deve expressar-se como "processo de classe na sociedade desigual, como um envolvimento com sujeitos e grupos produtores de cultura (o ponto de vista da preservação do humano através da cultura) e não com os produtos da cultura (o ponto de vista da manipulação do humano através da indústria cultural". (BRANDÃO, op. cit. p. 53)

Isto posto, não é difícil perceber a importância que as escolas de samba, como sendo esse lugar de produção cultural, e, como geradoras de conhecimentos que são, possam tornar-se em agências construtoras de subjetividades de indivíduos fazendo a inserção destes na linguagem, seja esta resultado da criação de um coletivo seja como mediadora do posicionamento político de novos sujeitos na cena urbana.

\section{A experiência do carnaval de Abaetetuba, sob o olhar do poder público}

Analisando a participação das escolas de samba de Abaetetuba no decênio 2004-2014, é revelador que o período tenha sido marcado pela oscilação com que o poder público municipal lidou com essa manifestação cultural. Tal oscilação, fosse ela marcada pela hegemonia desta ou daquela escola de samba, fosse pela não regularidade de uma política com que o poder público destinou a essas agremiações, fosse, ainda, mais recentemente, pela emergência de novos sujeitos na cena urbana do carnaval, o período em questão tornou-se significativo por vários aspectos.

No primeiro caso, no início da década (2001-2010), observava-se, ainda, a hegemonia de algumas escolas, tais como a 


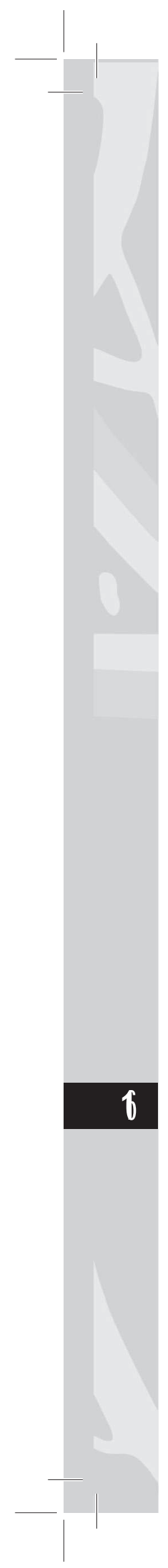

"Unidos da Praça", "Amigos da SOCIA" e "Acadêmicos do PSINTI", acompanhados pela presença de outras agremiações de porte mediano; por volta da metade da década, das três apenas duas permaneciam em atividade. A partir de 2006, apenas uma.

Este fato explica, por exemplo, de um lado, que tais mudanças podem estar diretamente vinculadas às políticas destinadas ao carnaval das escolas de samba e, por outro, à desmobilização ocorrida entre os produtores de carnaval os quais, percebendo a inviabilidade de seus respectivos projetos face a nova realidade carnavalesca que se lhes apresentava, optaram pelo encerramento de suas atividades. Um fator que contribuiu para o agravamento do quadro com que se deparavam as agremiações foi o descrédito e/ou desconfiança com que as mesmas passaram a ser olhadas pelo poder público e os munícipes, face a qualidade dos desfiles apresentados na avenida, sobretudo por agremiações de pequeno porte. Além disso, a falta de prestação de conta dos valores concedidos pelos cofres públicos destinados às agremiações, não chegavam a ser cobrados a posteriori, fato que gerava inúmeros problemas como a falta de transparência nos repasses. Este fato contribuiu para que a política de subvenção municipal assumisse sentido mais doméstico e clientelístico do que orgânico. Como decorrência desse processo, e da inoperância da Liga Independente do Carnaval Abaetetubense (LICA), criada em 2004, tais fatos corroboraram para que nos anos seguintes as entidades carnavalescas fossem afetadas mais ainda face ao desapoio municipal. Nos governos seguintes, as subvenções que porventura ocorreram passaram as ser vistas como meras despesas, em vez de investimentos na área social da cultura.

As experiências vivenciadas pelas escolas de samba no período aqui considerado (2004-2014), refletem dois projetos políticos sob os quais as agremiações carnavalescas estiveram adstritas. Em 2004, foi o último ano do mandato do Prefeito Francisco Maués Carvalho. Por tratar-se de fim de mandato, acredita-se que pelos registros coligidos devido à falta de recursos a serem destinados às escolas de samba e a ausência no desfile de agremiações como o "Acadêmicos 
do PSINTI" configurou-se como sendo um ano atípico. Assim, dadas as particularidades que o carnaval assumiu nesse $\mathrm{ano}^{4}$, tais fatores acabaram permitindo a emolduração de um novo cenário ditado agora pelas micaretas. A tradicional escola de samba "Amigos da SOCIA" ainda desfilara naquele ano com o enredo "60 anos viva Nina Abreu", arrebatando o título; o mesmo acontecendo no ano seguinte, quando defendeu o título com o enredo "SOCIA 10 anos de carnaval".

Em 2005, iniciara-se um novo período de governo, o do Sr. Luiz Gonzaga Leite Lopes, o qual se estenderia até 2008. Nesse período mereceu destaque o carnaval do primeiro ano. Marcado por pressão popular para que houvesse o desfile das escolas de samba, fato que se consubstanciou por meio de modesto subsídio às escolas e pela ausência de políticas públicas na área da cultura do carnaval o que permitiu a consolidação de outros projetos de "carnaval" como o dos "blocos de micaretas", iniciando-se a decadência do carnaval das escolas de samba. Nos anos seguintes, era visível a fragilidade das agremiações. Ainda em 2008, por tratar-se de ano eleitoral novas pressões foram feitas com vistas à promoção do carnaval. Nesse ano, já não mais participaria a campeã de 2005 uma vez que nos dois anos seguintes desestruturara-se, não tendo condições de organizar seu projeto de carnaval. Entre tais problemas, estavam os de ordem administrativa interna.

$\mathrm{Na}$ segunda fase do decênio aqui considerado (2009-2012), vige no Município outro projeto político-ideológico. Ele caracterizase pela relativa austeridade e racionalidade, pela negação à dimensão

\footnotetext{
${ }^{4}$ Existem inúmeros relatos acerca do encaminhamento do carnaval nesse ano: a falta de subvenção para geri-lo, o que teria provocado a criação do carnaval sob a forma de micareta, porém com o consentimento dos representantes das escolas à época, fato que não é confirmado por alguns deles. Em outros relatos, fica visível o interesse pela "economia da cultura" do carnaval e, nesse caso, já estava desenhado naquele processo a inserção das micaretas no espaço do carnaval tradicional, não passando a situação de manobras políticas por parte de agentes públicos com vistas à implantação da micareta como expressão válida e representativa do "carnaval" da cidade.
}

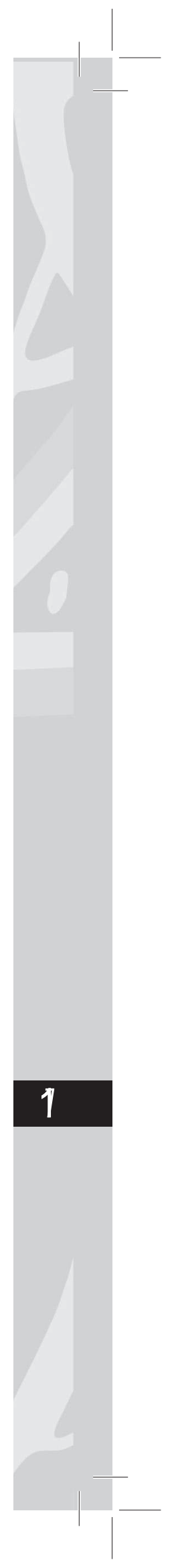




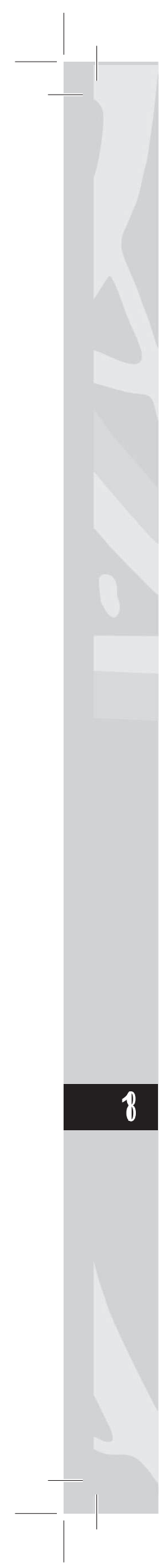

social da cultura do carnaval, motivadas sobretudo pelo que aqui denomino de "desapoio municipal". Definitivamente, as escolas de samba foram relegadas a segundo plano nas programações da Prefeitura, quando não abolidas. A subvenção às escolas não ocupou mais espaço na agenda municipal. Uma vez desarticuladas e sem incentivos regulares que justificassem a elaboração de projetos orgânicos vinculados ao carnaval, viram-se obrigadas a abandonarem suas pretensões.

Em 2011, ainda resistia a escola de Samba "Acadêmicos do PSINTI", que participaria do desfile naquele ano de forma modesta: uma ala de baianas, alguns destaques, antigos parceiros da escola e de velhos carnavais, o casal de mestre-sala e porta-bandeira e alguns colaboradores, além da bateria, cuja indumentária fora dada como parceria pelo Bloco Carnavalesco "Mocidade Independente "Acadêmicos do Samba", criado em fevereiro daquele ano. ${ }^{5} \mathrm{O}$ grupo de brincantes apareceria na programação da Prefeitura com a denominação de "Bloco Carnavalesco do PSINTI" e era conduzido na avenida por Orlando Cardoso Vilhena Júnior, presidente, puxador e autor do samba "Ele é nossa raiz". A letra do samba era um verdadeiro libelo ao público presente e às autoridades presentes naquele sábado de carnaval. Um protesto real e simbólico do sambista contra as condições a que chegara o carnaval das escolas de samba na cidade.

A experiência do carnaval de Abaetetuba no biênio 2013/2014 corresponde ao que denomino de "Reinscrição liminar da política de subvenção controlada". ${ }^{6}$ Tal experiência está vinculada às açõespiloto geradas a partir da implementação do projeto de pesquisa "Cultura e educação: Carnaval, cotidiano e processos educacionais em Abaetetuba" (1980/2011). O objetivo de tal projeto era fazer um estudo acerca dos processos educacionais na cultura do carnaval da

\footnotetext{
${ }^{5}$ O bloco parceiro, no ano seguinte, transformou-se na Escola de Samba "Acadêmicos de Samba Abaetetubense (A.S.A.) sendo atualmente a única escola a participar da programação de carnaval da Prefeitura Municipal da cidade.

${ }^{6}$ Cf. cap. 2 do estudo "Migalhas do carnaval. Escola de samba, educação e patrimônio etnográfico em Abaetetuba. 2014.
} 
cidade. Com isso, visava-se construir além do seu perfil o processo produtivo dessa prática, bem como elaborar estudo descritivo dos materiais produzidos por meio do carnaval enquanto patrimônio etnográfico e instância de resistência e de valorização da cultura local.

Entre tais ações, destacamos a realização de dois seminários ocorridos em 2011 ("Diálogos, experiências e resistência”), e 2012 ("Memória, patrimônio cultural e carnaval: Um diálogo necessário"). Eles serviram de substrato junto ao poder público, por meio de agentes públicos ligados à esfera da cultura no sentido de chamá-los a participar das discussões sobre a temática. Disso resultou que, a despeito da inexistência de projetos mais orgânicos por parte do poder público em relação a manifestações desenvolvidas por agremiações de carnaval, criou-se por parte da Fundação Cultural Abaetetubense, possibilidades ainda que incipientes, do reinteresse por uma nova forma de carnaval mediada pela regularidade, compromisso social e a participação de alguma forma com a comunidade, retirando, assim, os vícios de épocas passadas. Esta experiência é mais detalhada em outro trabalho (SILVA, 2014), no qual são apontadas as necessidades de políticas e de projetos na área da cultura tradicional como o carnaval. Segundo demostrou o estudo, as agremiações ou escolas de samba tidas como associações lúdicas e espontâneas ou como processo de identificação social que são, representam canais de diálogos da sociedade civil com o Estado. Dessa forma, dada a função social importante que assumem, as mesmas não podem de todo ser ignoradas. Além disso, a exclusão das associações carnavalescas do horizonte de expectativas do poder público revelam, de forma inconteste, que as políticas públicas na área da cultura precisam ser valorizadas como condição da participação plena da sociedade.

\section{A "economia da cultura" ou da ausência de políticas orgânicas ao "projeto do mercado"}

Observa-se no primeiro tópico deste estudo, de que maneira a cultura enquanto sistema de representação assume sua propriedade de instrumento de saber, de comunicação e maneira de se articular 


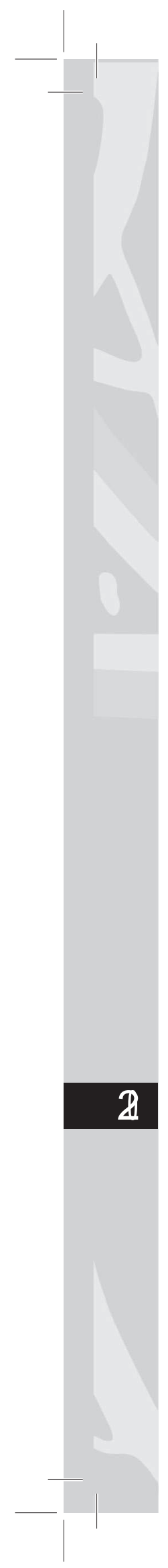

com o mundo. Opondo-se a essa perspectiva, porém, sem que isso represente uma ruptura ou excludência, e sim tão-somente complementaridade, a cultura também pode ser apreendida enquanto expressão política do poder dimensão na qual é identificada como uma categoria de forças entre categorias individuais. Ou, como bem observou Sérgio Miceli, "como um instrumento de poder, isto é, de legitimidade da ordem vigente" (MICELI, 1987, viii). A perspectiva tratada a seguir reflete um pouco dessa argumentação.

Os blocos de micareta na cidade de Abaetetuba que tradicionalmente concorrem a um calendário de festa conhecido como "carnaval fora de época" assumiram, a partir de 2005, durante o período momesco, o espaço destinado às escolas de samba. Os efeitos dessa mudança teve um significado político na produção do carnaval. Embora a emergência dos grupos micareteiros tenha sido gradual como mostramos em outro estudo (SILVA, 2012, 2014), a verdade é que a partir daquele ano houve uma espécie de consolidação desses grupos, em especial com a criação do "Bloco "Eq. do seu Dodô" que participara da programação oficial naquele ano, com mais de mil brincantes, estimulando a criação de outros, bem como assimilando segmentos das próprias escolas de samba. Isto se deveu entre outros aspectos ao fato de o trabalho que até então era desenvolvido pelas agremiações carnavalescas e mediado por relações de parentesco e de amizade, ancorados numa solidariedade de grupo, cedeu lugar a relações de trabalho assalariado, mediado pelo lucro imediato, advindo com as micaretas.

Assim, no momento que a especulação acerca do processo produtivo daquele modelo de "carnaval" começou a ganhar força por conta de novas formas de brincar o período de momo, e da influência da indústria cultural, exigindo menos envolvimento da comunidade e dando mais ênfase ao produto comercializado, nesse momento, como bem observou José Ramos Tinhorão (1997), as escolas de samba perderam seu referencial maior:

“... estará destruído o princípio básico da solidariedade de grupo que repousa na gratuidade da manifestação 
da cultura popular representada pelas escolas de samba. As escolas de samba estarão mortas e perderão a sua raiz folclórica, subindo ao céu da arte erudita e da promoção comercial ante as palmas da classe média - como um balão de gás....”. (TINHORÃO, op. cit. p. 97).

Há que se reconhecer que é a ausência de políticas orgânicas destinadas às manifestações tradicionais como o carnaval que permitiráa desmobilização das agremiações pela perda dos referenciais tradicionais (O samba, por exemplo). Segundo aponta Salles (2000), ao discorrer sobre em que condições a indústria cultural pode gerar o colonialismo interno "braço direito do colonialismo externo", ou a lacuna acima referida, o autor aponta entre outros fatores a construção de um projeto de "degradação cultural" porquanto "corrompe valores éticos e estéticos, destrói a memória e destrói a própria identidade cultural de um povo" (p. 8).

O cientista político Machado em "Notas sobre política cultural no Brasil (1984), escrevendo na década de 1980 observa de que forma nesse período predominou a baixa visibilidade social da política cultural no país, propondo:

retirá-lo do limbo em que se encontrava". Em tal estudo fez referência sobre a atuação das agências de fomento da área cultural as quais segundo ele eram mediadas ora por suas ações clientelísticas, ora por seu caráter assistencial, com reflexos diretos sobre o teatro (....), as manifestações das artes plásticas, e do chamado folclore em geral.

Assim, a admitir que o fato folclórico abrange as culturas populares, embora o conceito de cultura popular nem sempre abrange o folclore (SALLES, op. cit. p. 5), podemos inferir que o carnaval carrega também consigo aspectos dessa "raiz folclórica".

Ao discorrer sobre a importância da "arte como expressão das capacidades criadoras de um povo", o autor acima referido observa de forma categórica que "a cultura popular [e o carnaval] na sua maior 


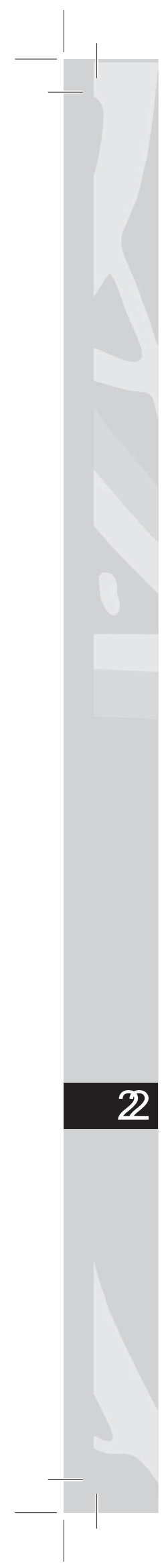

parte é menosprezada e assim aparece como uma outra expressão artística degradada" (Idem, p. 5). Com isso ele quer demonstrar que no âmbito das culturas populares, estas estão condenadas ao processo de higienização cultural permanente fazendo com que só adquira valor aquilo que o mercado de bens simbólicos e culturais considera como legítimo. Colocado nesses termos, uma pergunta se impõe: este não teria sido um dos motivos da implantação das micaretas em Abaetetuba em detrimento do carnaval tradicional, por julgarse aquele a representação do novo, do moderno e este o símbolo da tradição cristalizada, do velho, do arcaico, tendo na base disso a lógica imposta pela linguagem dos capitalistas da indústria cultural? A propósito, veja-se o fragmento a seguir. Ele revela, paradoxalmente, de que forma a falta de políticas orgânicas por parte do Estado na área das manifestações culturais tradicionais, é compensada pela construção do "projeto de mercado", ou seja, ditado pela indústria cultural, que chama para si a responsabilidade de gerir o mesmo, apoiado pelo Estado.

\begin{abstract}
A dimensão cultural ganha espaço com o empresariado cultural, com os fabricantes de festivais e carnavais extemporâneos $\star$, que avançam no bolso do trabalhador, muitas vezes com o apoio do poder público. Um dos resultados mais danosos da ação promíscua do poder público com o poder econômico, no caso da cultura

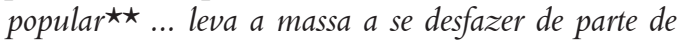
seus salários na compra dos chamados quites, além do pagamento de ingressos, largo consumo de bebidas, o fumo de variado sabor e entorpecentes. Muitas pessoas se rendem facilmente. É exigido apoio do Estado, no que diz respeito ao espaço e sua adequação e, em especial, à segurança pública, sabendo-se que os grupos mais organizados só se movimentam com seus próprios esquemas de som, transporte, hospedagem, serviços de boca e de segurança" (SALLES, op. cit. p. 6. * grifos meus; $\star \star$ grifos no original).
\end{abstract}

As observações acima servem de parâmetro para avaliar que no plano da cultura há que se reconhecer o processo de apropriação cultural. No caso referido, à medida que se constata a fragilidade na 
implementação de políticas públicas na área de cultura, em especial às práticas tradicionais das escolas de samba, reconfiguram-se propostas sobre estas práticas, que são colocadas na arena política, visando uma suposta homogeneização cultural. O caso da montagem dos projetos de carnaval para a cidade de Abaetetuba nos últimos anos, nele é visível o nivelamento feito com base nas micaretas como se constata neste fragmento.

O que se objetiva é a execução de um projeto no qual não há espaço à promoção social de incentivo à cultura e à diversidade dos movimentos populares, bem como à memória de sua preservação como grupos emolduradores da tradição e sim tão-somente a um conjunto normativo de regras contratuais com vistas a assumir um sentido significativamente mercadológico entre as partes envolvidas. Neste reduto construído a diversidade cede lugar à padronização cultural (SILVA, 2014).

Entretanto, se é possível implantar projetos cimentadores e hegemônicos com vistas a reforçar o status quo, também, da mesma forma, acredita-se ser possível resistir a essa padronização de valores. Nesse sentido, a experiência vivida pela escola de samba Acadêmicos de Samba Abaetetubense (A.S.A.), nos dois últimos anos (20132014) demonstrou que a despeito daquele projeto hegemônico conseguiu implantar seu projeto de carnaval baseado numa filosofia de valorização da história e da cultura local. Isto permitiu sua inserção no programa oficial de carnaval da Prefeitura da cidade com status de escola de samba ${ }^{7}$.

\footnotetext{
${ }^{7}$ No carnaval de 2014, não obstante participar das reuniões que antecedeu o desfile, e comunicar que participaria do mesmo, a escola de samba A.S.A. não teve seu nome inscrito na programação organizada pela Fundação Cultural Abaetetubense. Segundo se apurou, o problema fora gerado pela inabilidade de uma pessoa que por conta de mudanças na edição do material tenha retirado o nome da escola. Mas a escola não fora avisada com antecedência do problema.
}

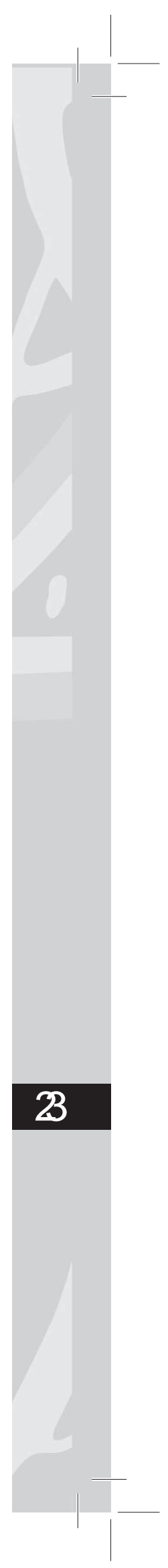




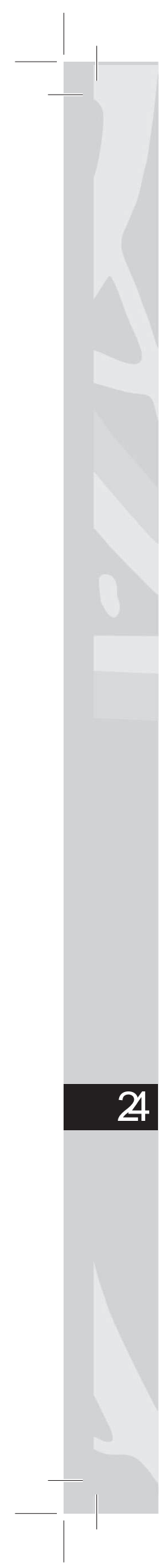

Isto posto, pode ser avaliado como um indicador que serve para desconfigurar a ideia de um universalismo cultural como ideologia dominante, e sinaliza o fato que a singularidade cultural resiste à globalização, e nessa condição, como localismo crítico que é, pode se transformar em instância de resistência cultural. A experiência cultural e trajetória das práticas carnavalescas desenvolvidas pela escola de samba A.S.A. acima referida dá sinais dessa resistência.

\section{Considerações finais}

Um dos graves problemas na relação Estado-Cultura reside na incompreensão por parte do poder público, no caso aqui tratado, do que venha a ser cultura e suas propriedades em sua dimensão antropológica. Não raro, ela é interpretada no nível do senso comum, ou seja, como se fosse constituída apenas das expressões culturais, transformadas em espetáculos ou produto a ser exibido. Este aspecto tem guindado a realidade cultural a uma visão reificada à medida que não se consegue interpretá-la enquanto um sistema de representação.

Essa experiência é atualizada de forma recorrente no âmbito do poder público local. Talvez, isso tenha servido de escudo na relação Estado, sociedade civil e a realidade cultural. Se de um lado ocorrem lacunas no âmbito das políticas públicas direcionadas às manifestações culturais tradicionais como o carnaval, isso se deve ao fato da desimportância que tem sido dado a ela e a outras formas culturais por conta daquela incompreensão. Além disso, a análise feita permite apontar que na base do problema está, também, a dificuldade de ordem política que faz com que o poder público municipal não consiga articular ações que estão na base da própria dinâmica dos serviços e agendas da política cultural a nível nacional, como é o caso da necessidade de criação de seu Plano Municipal de Cultura.

A despeito das implicações acima apontadas, tal fato gerou a transferência para a sociedade civil de competências que 
originariamente eram suas, ou concedendo aos empresários da indústria cultural a possibilidade de explorar a "economia da cultura" e, ao compartilhar dela, acabou gerando uma espécie de "degradação cultural”. Em contraposição, contudo, a prática política do cotidiano tem mostrado que o universalismo cultural como ideologia dominante não se sustenta diante da singularidade cultural, que aposta no local da cultura como forma de resistência.

\section{REFERÊNCIAS}

ARANTES, Antônio Augusto. O que é cultura popular. São Paulo: Brasiliense, 1995.

AUGRAS, Monique. O Brasil do samba-enredo. Rio de Janeiro: Editora da Fundação Getúlio Vargas, 1998.

BRANDÃO, Carlos Rodrigues. Cultura, Estado e Sociedade. In: O Ardil da ordem. Campinas, São Paulo: Papirus, 1983.

BOSI, Alfredo. Cultura como tradição. In: BORNHEIM, G. et al. (Org.). Cultura brasileira. Tradição/Contradição. Rio de Janeiro: Jorge Zahar Editor; FUNARTE, 1987.

MACHADO, Mário Brokmann. Notas sobre política cultura no Brasil. In: MICELI, Sérgio. (Org.) Estado e cultura no Brasil. São Paulo: Difel, 1984.

MICELI, Sérgio. A força do sentido. In: BOURDIEU, Pierre.

A economia das trocas simbólicas. São Paulo: Perspectiva, 1987.

SALLES, Vicente. Colonialismo e indústria cultural. In: Jornal Lúcio Flávio Pinto/Agenda Amazônica, Belém, 2000.

SILVA. Dedival Brandão da. Carnaval em Abaetetuba. História, apropriação cultural e resistência. In: Bricio, Vilma Nonato de; 
Sarmento-Pantoja, Augusto;

(Org.). Cultura, educação

e Pesquisa na Amazônia. Rio de Janeiro: Oficina Raquel, 2012.

Migalhas do Carnaval. Escolas de samba, educação e patrimônio etnográfico em Abaetetuba. 2014.

TINHORÃO, José Ramos. Música popular: um tema em debate. São Paulo: Editora 34, 1997. 